\title{
Structural and Photoelectrochemical Properties of Cu-Doped CdS Thin Films Prepared by Ultrasonic Spray Pyrolysis
}

\author{
Rui Xie, Jinzhan Su, Mingtao Li, and Liejin Guo \\ International Research Center for Renewable Energy, State Key Laboratory of Multiphase Flow in Power Engineering, \\ Xian Jiaotong University, Xian 710049, China \\ Correspondence should be addressed to Liejin Guo; lj-guo@mail.xjtu.edu.cn
}

Received 6 December 2012; Accepted 13 January 2013

Academic Editor: Shaohua Shen

Copyright (C) 2013 Rui Xie et al. This is an open access article distributed under the Creative Commons Attribution License, which permits unrestricted use, distribution, and reproduction in any medium, provided the original work is properly cited.

$\mathrm{Cu}$-doped CdS thin films of variable doping levels have been deposited on indium tin oxide-coated glass substrate by simple and cost-effective ultrasonic spray pyrolysis. The influences of doping concentration and annealing treatment on the structure and photoelectrochemical properties of the films were investigated. The deposited films were characterized by XRD, SEM, and UV-Vis spectra. Moreover, the films were investigated by electrochemical and photoelectrochemical measurements with regard to splitting water for solar energy conversion. The results showed that the $\mathrm{Cu}$ impurity can cause a structural change and red shift of absorption edge. It was found that the photocurrent can be improved by the $\mathrm{Cu}$-doping process for the unannealed films under the weak illumination. The unannealed 5 at.\% Cu-doped sample obtained the maximum IPCE, which achieved about $45 \%$ at $0.3 \mathrm{~V}$ versus SCE potential under $420 \mathrm{~nm}$ wavelength photoirradiation. In addition, the p-type CdS was formed with a doping of 4 at. $\% \sim 10$ at. $\%$ $\mathrm{Cu}$ after $450^{\circ} \mathrm{C} 2 \mathrm{~h}$ annealed in vacuum.

\section{Introduction}

Hydrogen is widely considered to be the energy carrier of the future. The most promising method, environmentally friendly, of hydrogen generation is based on photoelectrochemical water decomposition using solar energy [1]. The crucial problem of this method is an appropriate choice of the suitable photoanode material. Many oxide photoelectrodes such as $\mathrm{TiO}_{2}, \mathrm{WO}_{3}, \mathrm{ZnO}$, and $\mathrm{SrTiO}_{3}$ have been extensively studied for hydrogen production during the past decades [26]. However, due to their wide band gaps, these oxides can respond only to ultraviolet (UV) light, the energy of which makes up only a small fraction of the solar spectrum. For enhancing the efficiency of light conversion, it is necessary to develop semiconductor photoelectrodes with suitable band gap to work under visible light irradiation [7]. Many efforts have been made to modify these oxide materials to visible response [8-10].

In contrast to these metal oxide photoelectrodes, many metal sulfides such as CdS have narrower band gaps that correspond to the visible light. Pristine CdS is known to show $\mathrm{n}$-type characteristics due to the intrinsic defects [11]. It has generally been considered that the formation of p-type CdS is very difficult, because of strong self-compensation effect due to sulphur vacancies $[11,12]$. Cu doping was regularly conducted to form p-type CdS. The doping procedure was always by $\mathrm{Cu}$ element diffusion from a copper layer over the CdS layer with annealing process $[13,14]$. Some other ways such as electrochemical deposition [15], chemical bath deposition [16], vacuum deposition [17], and pulsed laser deposition [18] have been tried to form p-type CdS. Ultrasonic spray pyrolysis as a simple and cost-effective method is widely used for the preparation of sulfide and oxide thin films [19]. Ultrasonic nebulized atomization provides a method to get droplets of precursor with extremely small sizes. As the droplets approach the heated substrate, the reactants diffuse to the substrate, and a heterogeneous reaction occurs, which led to the formation of thin films. In this paper, $\mathrm{Cu}$-doped $\mathrm{CdS}$ thin films were prepared by an ultrasonic spray pyrolysis aqueous precursor, and some properties of the deposited films such as structural, morphologic, optical, and photoelectrochemical characteristics were examined to find out the probability of efficiency improving in water splitting application. 


\section{Experimental}

2.1. Preparation of Films. Cu-doped $\mathrm{CdS}$ thin films were prepared by ultrasonic spray pyrolysis method with a locally fabricated ultrasonically nebulizing spray pyrolysis apparatus, which was similar to the apparatus used in [20]. ITO-coated glass $\left(15 \Omega /\right.$ sq.) with dimensions of $60 \times 20 \times 1.1 \mathrm{~mm}^{3}$ heated at $300^{\circ} \mathrm{C}$ was used as substrate. The substrate temperature was calibrated by fixing a k-type thermocouple temporarily on the surface of the substrate and simultaneously measuring the heat plate temperature. Some additional parameters such as the distance between the hot plate and nozzle, the carrier gas (nitrogen, $\mathrm{N}_{2}$ ) flow rate, and the velocity of the nozzle motion were optimized previously to get good quality films. In all our experiments the flow rate of carrier gas was fixed at $0.2 \mathrm{~m}^{3} / \mathrm{h}$. The intensity of oscillation of the PZT (piezoelectric transducer), the scan length, the velocity of the nozzle, and the times of scanning motion were all kept constant.

A mixed aqueous solution of cadmium chloride, thiourea and copper chloride was used as the precursor solution to deposit $\mathrm{Cu}$-doped $\mathrm{CdS}$ thin films. At first, the aqueous solutions of cadmium chloride $(0.05 \mathrm{M})$ and thiourea $(0.055 \mathrm{M})$ were prepared, respectively. A solution of copper chloride $(0.005 \mathrm{M})$ was obtained by adding excess EDTA to copper chloride solution and maintaining in $80^{\circ} \mathrm{C}$ water bath for $30 \mathrm{~min}$. Then, a fixed volume of mixed aqueous solution was got by taking equal volume $(20 \mathrm{~mL})$ of cadmium chloride and thiourea. After that, the variable volume of copper chloride was added into the above-mentioned mixed aqueous solution with constant stirring.

After deposition, samples were subsequently cooled naturally to room temperature in air. Then each sample was cut into four pieces with dimensions of $15 \times 20 \times 1.1 \mathrm{~mm}^{3}$, two of which would be annealed in vacuum at $450^{\circ} \mathrm{C}$ for two hours. Ohmic contacts were made on the non-CdS-coated part of ITO using $\mathrm{Cu}$ wire with the help of silver glue and sealed with epoxy resin. The assembled working electrodes have surface areas varying from 0.8 to $1.3 \mathrm{~cm}^{2}$.

2.2. Film Characterization. The surface morphology of films was recorded using a model JSM-6700F field emission scanning electron microscopy (SEM) from JOEL. The structural analysis of as-prepared films was performed by $\mathrm{X}$ ray diffraction (XRD) employing a model X'Pert PRO Xray diffractometer from PANalytical equipped with $\mathrm{Cu} \mathrm{Ka}$ irradiation. Optical absorption spectra were recorded in the wavelength range of 300-800 $\mathrm{nm}$ using a model UV4100 UVVis-NIR Spectrophotometer from Hitachi equipped with an integrating sphere.

Photoelectrochemical measurements were performed in a custom made cell equipped with a quartz window. The cell set up was made up of a working electrode (the deposited sample), a counter electrode (round-shaped platinum wafer with diameter of $1.8 \mathrm{~cm}$ and thickness of $0.1 \mathrm{~cm}$ ), and a reference electrode (SCE, saturated calomel electrode). The measurements were performed at ambient temperature $\left(22^{\circ} \mathrm{C}\right)$ employing an EG and G Princeton Applied Research Model 273A potentiostat and a SIGNAL RECOVERY model 5210 lock-in amplifier. The electrolyte for the capacitance measurements which were carried out at dark was $0.5 \mathrm{M} \mathrm{KOH}(\mathrm{pH}=$ 13.6). While the electrolyte for the action spectra and linear sweep voltammetry measurement was $0.5 \mathrm{M} \mathrm{Na}_{2} \mathrm{SO}_{3}$. In the linear sweep voltammetry a $350 \mathrm{~W}$ Xe lamp was used as light source whose intensity was determined by a radiometer (FZA, Beijing Normal University, China). While in the measurement of photocurrent action spectra, the light source was the same $350 \mathrm{~W}$ Xe lamp with its output chopped with a model 197 chopper (SIGNAL RECOVERY) and monochromated with an Computer Controlled monochromator (WGD302, BOIF, China), and its intensities were calibrated with an IL1400BL radiometer (International Light, Inc.) equipped with an SEL033 sensor head. The IPCE (the Incident Photon to Electron Conversion Efficiency) was calculated via the formula in [9] without correction for the reflection loss of the quartz window and the absorption loss of the electrolyte.

\section{Results and Discussion}

3.1. Structure and Morphology. The deposited films appear transparent, smooth, and uniform to the eye, while their colors became darker with higher doping level. Figure 1 shows SEM pictures of six of the samples. It was observed that the diameters of particles in the films decrease and then increase with increasing the amount of $\mathrm{Cu}$ doping. The 1 at.\% $\mathrm{Cu}-$ doped CdS particle has the smallest diameter. This should be a result of the crystalline structure change, as will be demonstrated shortly by XRD analysis, due to $\mathrm{Cu}$ doping. The inset of Figure 1(d) shows the cross-sectional view of 2 at.\% $\mathrm{Cu}$-doped CdS film. It confirmed the uniformity of the films and exhibited three layers in which the bottom layer was the glass, the interlayer was ITO, and the top layer was the CdS film with a thickness of about $284 \mathrm{~nm}$.

The results of the structural analysis of the undoped and $\mathrm{Cu}$-doped CdS thin films by XRD are shown in Figure 2. All the XRD peaks in all samples corresponded to those of hexagonal CdS (JCPDF 01-080-0006) except two ITO's peaks (marked by “*, "JCPDF 01-089-4597) in the 10 at.\% $\mathrm{Cu}$-doped sample. No peak corresponds to $\mathrm{CuS}$ or $\mathrm{Cu}_{2} \mathrm{~S}$, indicating that no crystalline $\mathrm{CuS}$ or $\mathrm{Cu}_{2} \mathrm{~S}$ phase was formed. In the low doping level a (002) preferred orientation was observed, while in the high doping level this preferred orientation disappeared. As the concentration of $\mathrm{Cu}$ increase the peak intensities of (100) (101) (110) (112) direction increase, while that of (002) and (103) direction decrease. So it was thought that the $\mathrm{Cu}$ doping provoked a crystalline structure change, which caused a change of morphology that was shown by SEM images. For the annealing samples, the XRD pattern did not change significantly after annealed in vacuum, which means that annealing treatment does not improve the crystalline quality anymore.

3.2. Optical Characteristics. The UV-Vis spectra of unannealed samples are shown in Figure 3. Two absorption edges were observed at $517 \mathrm{~nm}$ and $650 \mathrm{~nm}$ corresponding to $2.4 \mathrm{eV}$ and $1.9 \mathrm{eV}$, respectively. The absorption strength in the wavelength range between $517 \mathrm{~nm}$ and $650 \mathrm{~nm}$ increases 


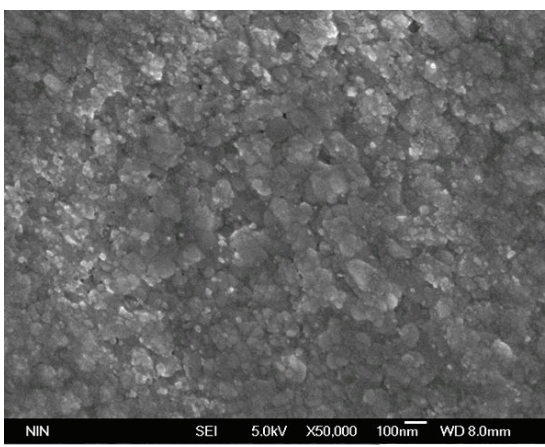

(a)

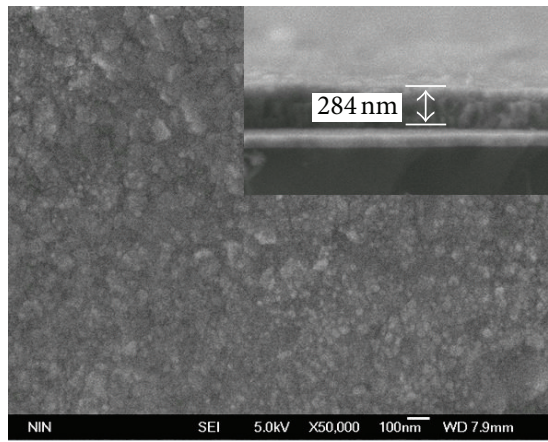

(d)

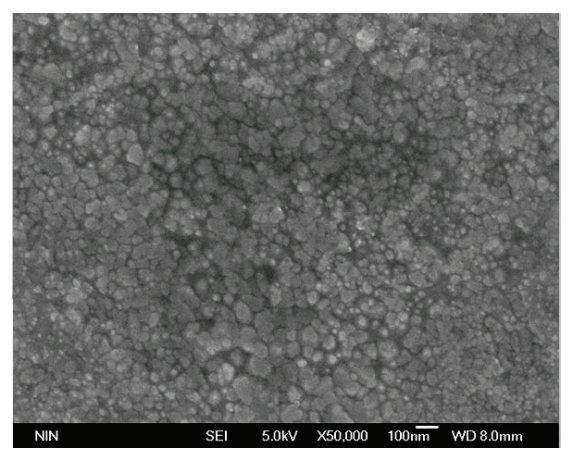

(b)

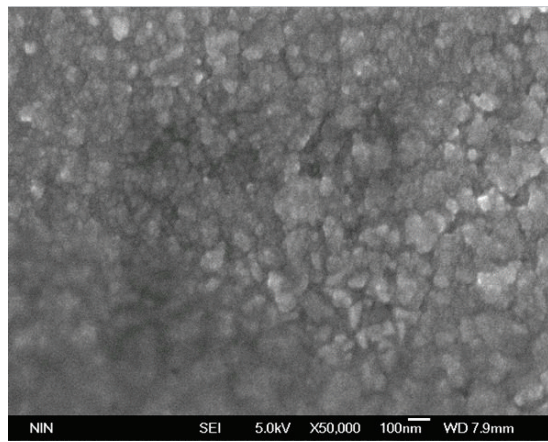

(e)

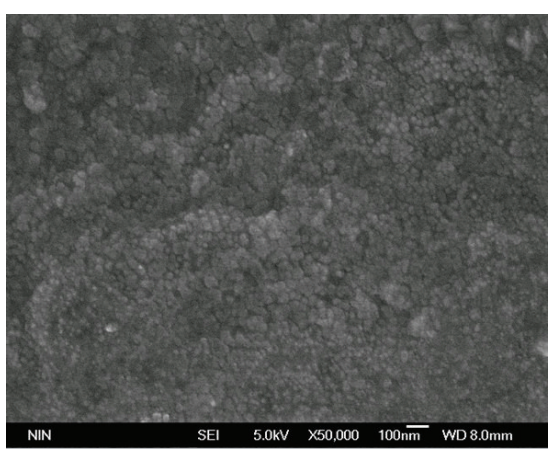

(c)

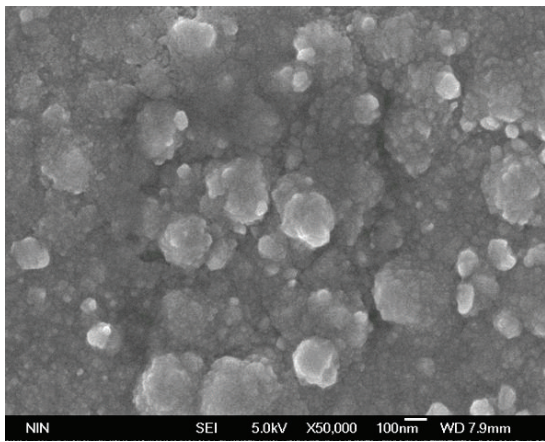

(f)

Figure 1: SEM images of Cu-doped CdS films: (a) 0 at.\% doped, (b) 0.5 at.\% doped, (c) 1 at.\% doped, (d) 2 at.\% doped (inset is its crosssectional view), (e) $4 \%$ at. $\%$ doped, and (f) $5 \%$ at. $\%$ doped.

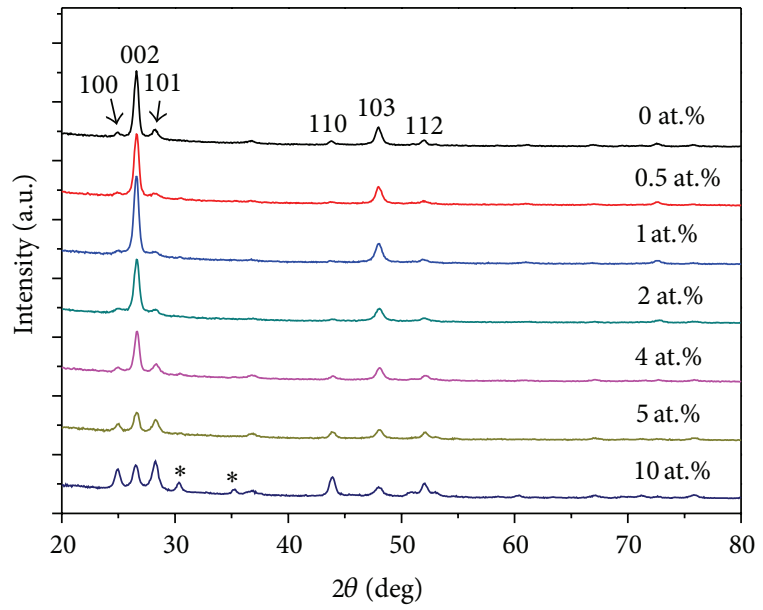

FIGURE 2: XRD patterns of $\mathrm{Cu}$-doped $\mathrm{CdS}$ films with different doping levels.

with higher dopant concentration, which indicates that the light absorption in this wavelength range is provoked by $\mathrm{Cu}$ doping. A close value of $2.0 \mathrm{eV}$ for the absorption edge of $\mathrm{Cu}$-doped $\mathrm{CdS}$ was obtained by Sebastian [16]. It was assumed that the dopant of $\mathrm{Cu}$ gives a level situated at about $0.5 \mathrm{eV}$ above the top of the valence band of the host CdS. The absorption edge of $650 \mathrm{~nm}$ may result from excitation from $\mathrm{Cu}$ level to conduction band (CB). Substitutional $\mathrm{Cu}$ on a Cd site is expected to be a single acceptor, whose ionization level is located at $0.6 \mathrm{eV}$ above the valance band (VB). But interstitial $\mathrm{Cu}$ which is expected to be a single donor has two ionization levels: one is at $0.7 \mathrm{eV}$ below the $\mathrm{CB}$, and the other is just below the $\mathrm{CB}$ [21]. Our estimated $\mathrm{Cu}$ level is close to ionization level of substitutional $\mathrm{Cu}$, and the XRD characteristic peaks of all samples have no obvious shift, which may be infer that the Cu doping of our CdS films occurs by substitution of $\mathrm{Cd}$ ions with $\mathrm{Cu}$ ions in the lattice, rather than $\mathrm{Cu}$ ions occupying the interlattice sites. In addition, the UV-Vis spectra of annealed samples not shown here have no obvious changes with that of unannealed samples.

\subsection{Electrochemical and Photoelectrochemical Characteristics.} Figure 4 illustrates Mott-Schottky plots of unannealed $\mathrm{Cu}$ doped CdS with different doping levels. At low dopant concentration (0 2 at.\%), the films reveal n-type semiconducting behavior, as positive slopes were obtained whose value increased with higher dopant concentration, indicating that the donor densities are reduced by the compensation of $\mathrm{Cu}$ acceptor. At higher dopant concentration (4 10 at.\%), the films exhibit a different behavior. The 4 at.\% doped and 10 at.\% doped samples give both positive and negative slopes in their Mott-Schottky plots which means that they reveal both n-type and p-type characteristics [22]. We ascribe this duplex character behavior to the $\mathrm{Cu}$ atoms unevenly distributed in the host CdS film. In contrast with other samples, the 5 


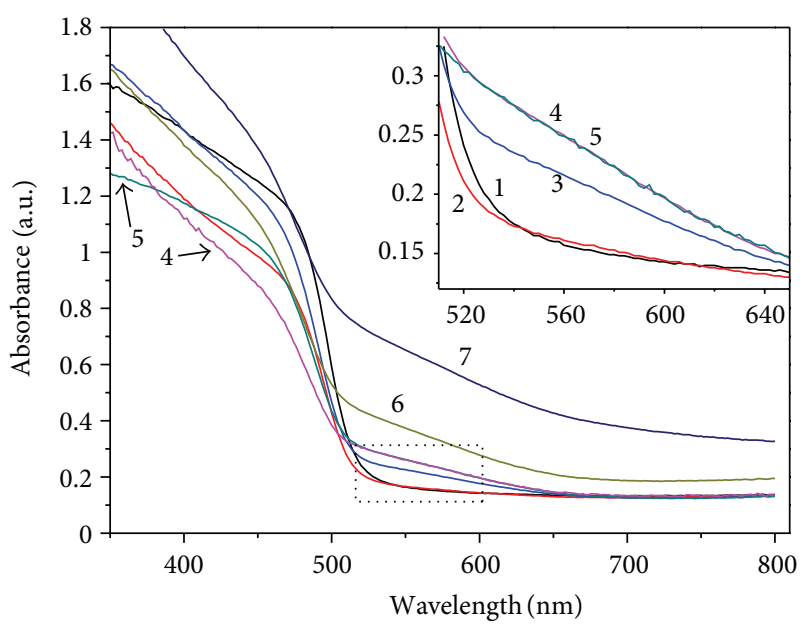
(1) $\mathrm{Cu} \%=0$
(5) $\mathrm{Cu} \%=4$
(2) $\mathrm{Cu} \%=0.5$
(6) $\mathrm{Cu} \%=5$
(3) $\mathrm{Cu} \%=1$
(7) $\mathrm{Cu} \%=10$
(4) $\mathrm{Cu} \%=2$

Figure 3: UV-Vis spectra for Cu-doped CdS films with different doping levels.

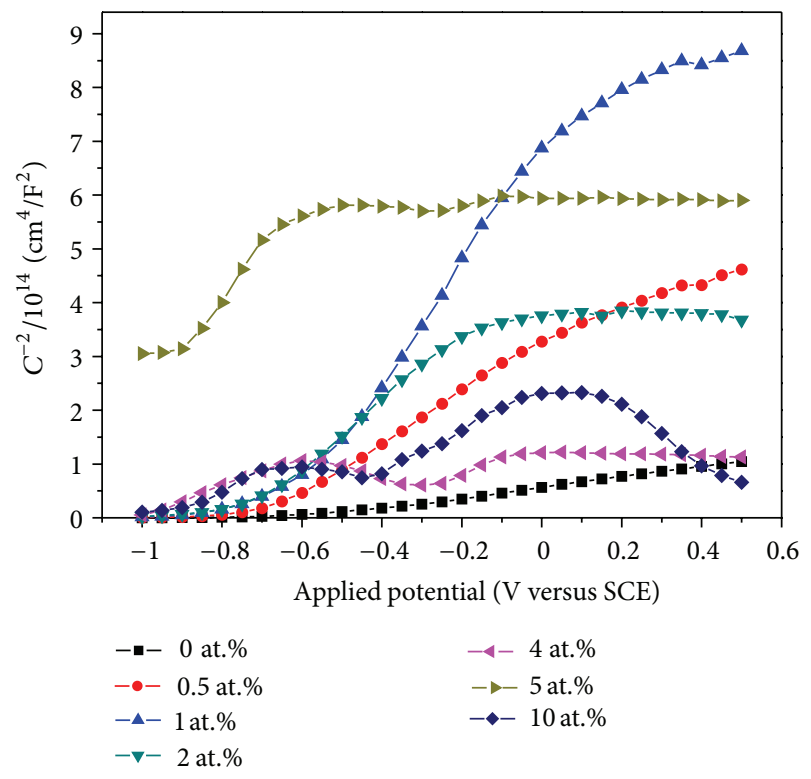

FIGURE 4: Mott-schottky plots of unannealed Cu-doped CdS films with different doping levels.

at.\% doped sample is entirely different whose capacitance value does not change significantly with different electrode potentials. Thus, this film behaves as a capacitor or more probably as a low doped-like semiconductor [22]. That should result from the equality strength of effects from $\mathrm{Cu}$ acceptors and defect donors (such as $S$ vacancy).

Mott-Schottky plots for the annealed samples are represented in Figure 5. The low doped ( 0.5 at.\% and 1 at.\%) CdS films do not showing n-type characteristic after annealing but behave like unannealed 5 at.\% doped $\mathrm{CdS}$ as a low doped-like semiconductor [22]. The annealed 2 at.\% doped CdS reveals both $\mathrm{n}$-type and p-type characteristics. With the dopant concentration getting higher than 4 at.\%, the conversion of conductivity type from n-type to p-type was observed for the annealed $\mathrm{Cu}$-doped $\mathrm{CdS}$. This annealing effect on the conductivity type that should ascribe to the $\mathrm{Cu}$ atoms become uniformly distributed in the host CdS film after annealing.

Figure 6 shows wavelength dependence of IPCE (incident photon-to-current conversion efficiencies) for CdS electrodes with different dopant concentrations unannealed or annealed at $450^{\circ} \mathrm{C}$ in vacuum. These curves clearly show the occurrence of longer wavelength response (red shift) as a result of $\mathrm{Cu}$ doping, as is expected from UV-Vis absorption spectra (Figure 3). The threshold wavelength is around $680 \mathrm{~nm}$ (corresponding to $1.82 \mathrm{eV}$ ), which is $30 \mathrm{~nm}$ longer than the absorption spectra result $(650 \mathrm{~nm})$. The IPCE in the red shift region increases with higher dopant concentration before the dopant concentration of 5 at.\% but gets a little lower for the 10 at.\% doped sample. The IPCE in the fundamental absorption region are also improved after $\mathrm{Cu}$-doped. The photocurrent in this region should be derived from the exciting of electron from valence band to conduction band. It was thought that an nonuniform distribution of $\mathrm{Cu}$ atoms in the host CdS films was formed due to a asynchronous formation of $\mathrm{Cd}-\mathrm{S}$ bond and $\mathrm{Cu}-\mathrm{S}$ bond during the pyrolysis, and this nonuniform distribution of $\mathrm{Cu}$ atoms caused formation of disordered tiny local $\mathrm{p}-\mathrm{n}$ junctions in the films. The $\mathrm{Cu}$ acceptors may decrease the photocurrent by acting as a recombination center, but the disordered local $p-n$ junctions separated the generated electrons and holes and improved the photocurrent. The maximum IPCE achieved $45 \%$ at $420 \mathrm{~nm}$ under $0.3 \mathrm{~V}$ versus SCE potential for the 5 at.\% doped sample.

As show in Figure 6(b), the IPCE of the annealed films increases by $18 \%$ at low dopant level $(0.5$ at.\% and 1 at.\% doped) but decreases dramatically when the dopant concentration gets higher than 2 at.\%. The reason for this should be the high concentration of $\mathrm{Cu}$ acceptors which function as a recombination center. And there were no more local $\mathrm{p}-\mathrm{n}$ junctions in the films because they were eliminated by uniformly dispersing of $\mathrm{Cu}$ atoms which was caused by the annealing treatment.

Figure 7 shows a plot of the photocurrent density versus applied potential obtained by linear sweep voltammetry measurement in which a shutter was used for evaluating the anodic current both in dark and light conditions. The illumination light here was white light from Xe lamp with an intensity of $165 \mathrm{~mW} / \mathrm{cm}^{2}$. It was observed that the photocurrents diminished after $\mathrm{Cu}$ doping. The undoped film has the highest photocurrent of approximately $5.1 \mathrm{~mA} / \mathrm{cm}^{2}$ at $0.3 \mathrm{~V}$ versus SCE. For the annealed $\mathrm{Cu}$-doped films, the photocurrents, which were not shown here, dropped even more dramatically after doping.

The decrease of photocurrent after doping under the white light illumination was corresponding to the high carrier recombination rate. This is different from the result of IPCE measurement. The reason for this difference should 


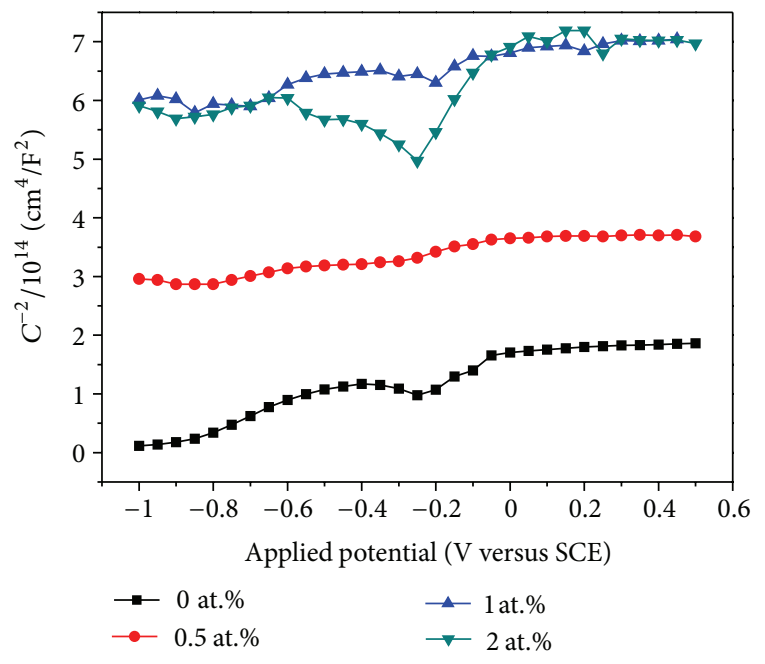

(a)

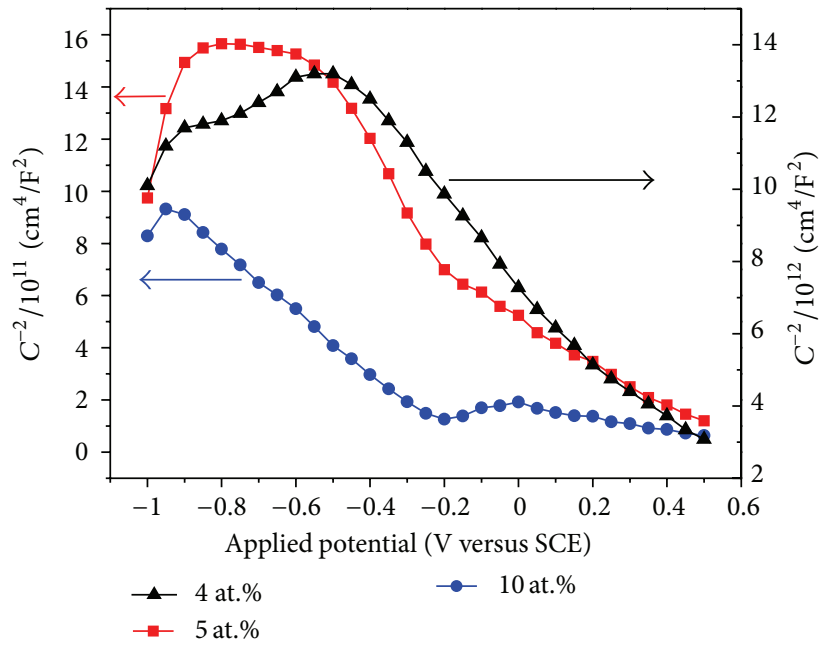

(b)

Figure 5: Mott-schottky plots of (a) 0 at.\%, 0.5 at.\%, 1 at.\%, and 2 at.\% Cu-doped samples and (b) 4 at.\%, 5 at.\%, and 10 at.\% Cu-doped samples. (All samples were annealed.)

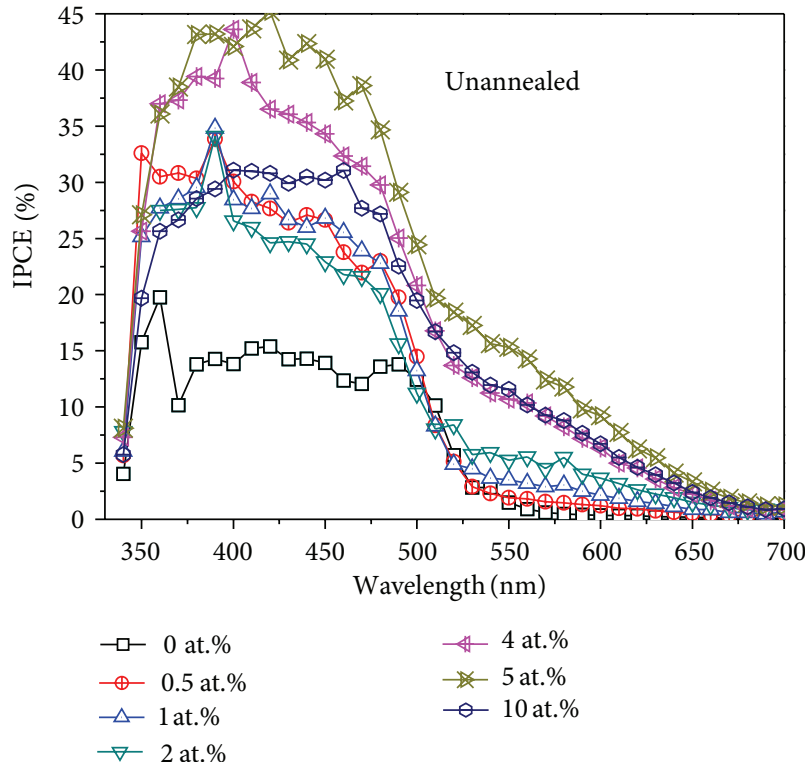

(a)

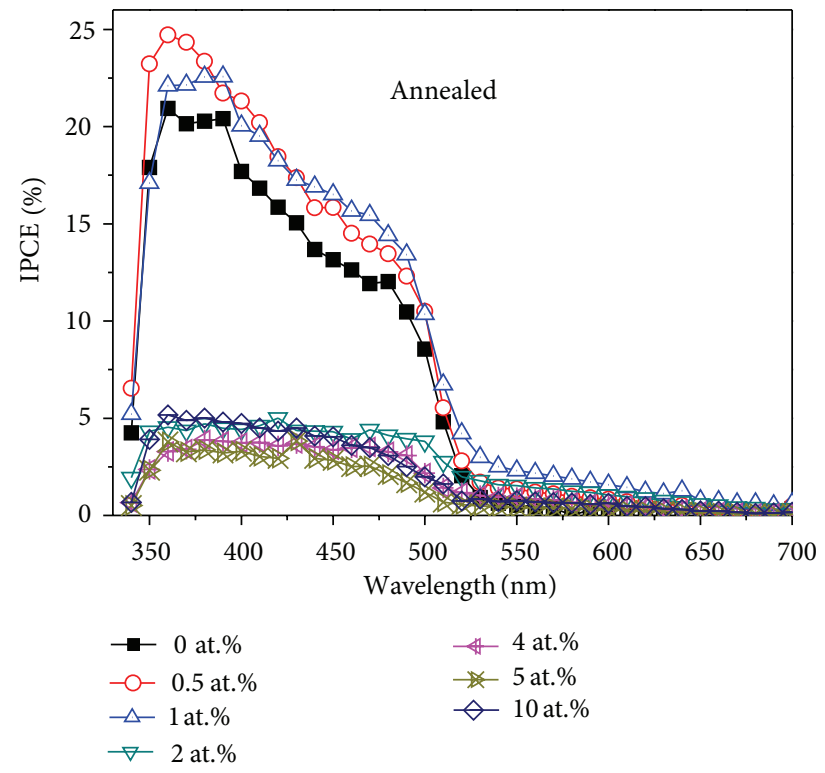

(b)

Figure 6: Photocurrent action spectra of (a) unannealed and (b) annealed Cu-doped CdS films with different doping levels. (The electrode potential is fixed at $0.3 \mathrm{~V}$ versus $\mathrm{SCE}$ in $0.5 \mathrm{M} \mathrm{Na}_{2} \mathrm{SO}_{3}$ aqueous solution.)

be the different intensity of the illumination light. The IPCE measurement was taken using the weak monochromatic light $\left(130 \sim 750 \mu \mathrm{W} / \mathrm{cm}^{2}\right)$, while in the linear sweep voltammetry measurement an intense white light was utilized $\left(165 \mathrm{~mW} / \mathrm{cm}^{2}\right)$. The large difference of the light intensity causes the variation of the photocurrent response in these two measurements. Under the weak light illumination the electron-hole pairs were spatially separated by the disordered local p-n junctions and then the separated electrons and holes drifted towards the side of substrate and electrolyte, respectively, due to the electric field within the space-charge region, so the efficiency could be relatively high for the weak illumination. It was reported that the electron lifetime decreases with increasing light intensity [23], so the recombination of electrons and holes can be higher under the intense white light illumination, causing the photocurrent drop of the $\mathrm{Cu}$-doped samples. In addition, the electric field in the space-charge region diminished under the intense white light 


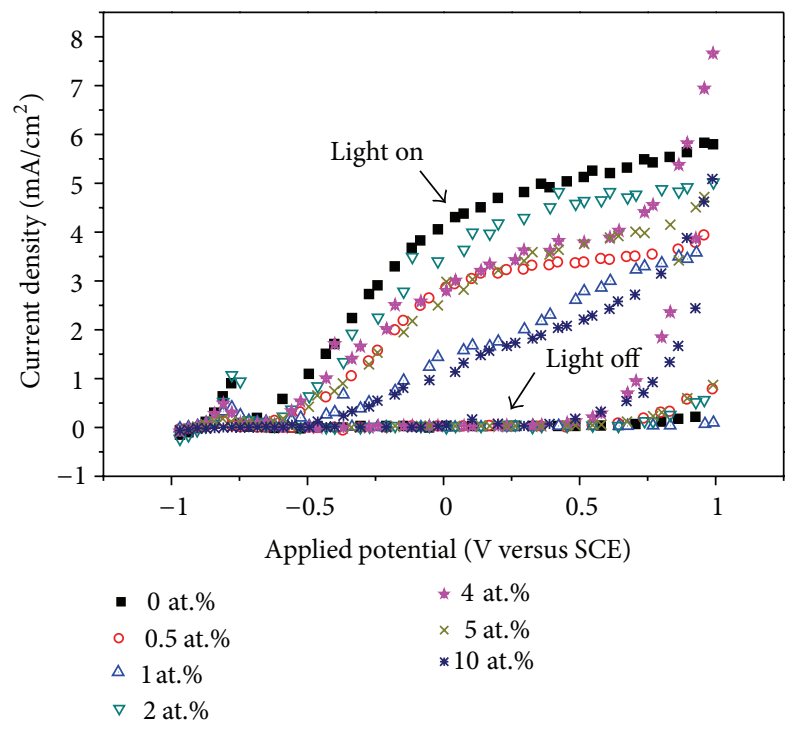

FIGURE 7: Photocurrent density versus applied potential for the unannealed $\mathrm{Cu}$-doped $\mathrm{CdS}$ films with different doping levels recorded in $0.5 \mathrm{M} \mathrm{Na}_{2} \mathrm{SO}_{3}$ solution, illumination at an intensity of $165 \mathrm{~mW} / \mathrm{cm}^{2}$.

illumination, then the local p-n junctions separated electrons and holes could not be further separated and recombined before they reached the substrate or the electrolyte side.

\section{Conclusions}

The present work demonstrated $\mathrm{Cu}$-doped CdS films synthesized by ultrasonic spray pyrolysis with $\mathrm{Cu}^{2+}$ containing agent added into precursor directly. The morphology changed with $\mathrm{Cu}$ doping. The diameters of particles in the films decrease and then increase with increasing amount of $\mathrm{Cu}$ dopant. In this alteration of diameter changing direction, the (002) preferred orientation disappeared. The $\mathrm{Cu}$ doping causes a red shift of absorption edge from $517 \mathrm{~nm}$ to $650 \mathrm{~nm}$, and the absorption strength increase with higher dopant concentration.

The unannealed films reveal n-type semiconducting behavior at dopant concentration lower than 2 at.\% and both n-type and p-type characteristics at dopant concentration higher than 4 at.\%. After annealing none of the doped films show n-type anymore. Only the annealing samples with more than 4 at.\% $\mathrm{Cu}$-doped films reveal p-type characteristic. Other samples reveal complex conducting characteristics.

The IPCE was improved by $\mathrm{Cu}$ doping for the unannealed samples. A maximum IPCE of $45 \%$ was got at $420 \mathrm{~nm}$ for the 5 at.\% doped sample. But for the annealed samples, only that of 0.5 at.\% and 1 at.\% doped samples were slightly improved. IPCE of $2 \sim 10$ at.\% doped samples decreased dramatically. Under intensity illumination, the photocurrent of all the doped samples decreased. In the linear swept voltammetry measurement, charge separation efficiency in the space charge region was dependent on the illumination intensity. It decreased as the illumination intensity increased.
The p-type CdS can only be formed by high level doping (more than 4 at.\%) and then annealing to make $\mathrm{Cu}$ element uniformly dispersible. But the doping caused a dramatically decrease of photocurrent. This p-type CdS deposition could not be thought to be advantageous, but as the unannealed $\mathrm{Cu}$-doped samples give an increase in efficiency under weak illumination, which was ascribed to formation of disordered local $p-n$ junction in the film, it can be said that this gives a new way easy to grasp to improve the separation of electronhole pairs in the photoelectrochemical cells.

\section{Acknowledgments}

The authors gratefully acknowledge the financial supports from the National Natural Science Foundation of China (Contract no. 51121092, no. 51202186) and the National Basic Research Program of China (no. 2009CB220000). One of the authors (J. Su) was supported by the the Fundamental Research Funds for the Central Universities.

\section{References}

[1] A. Mills and S. Le Hunte, "An overview of semiconductor photocatalysis," Journal of Photochemistry and Photobiology A, vol. 108, no. 1, pp. 1-35, 1997.

[2] T. Bak, J. Nowotny, M. Rekas, and C. C. Sorrell, "Photoelectrochemical hydrogen generation from water using solar energy. Materials-related aspects," International Journal of Hydrogen Energy, vol. 27, no. 10, pp. 991-1022, 2002.

[3] K. Rajeshwar, "Hydrogen generation at irradiated oxide semiconductor-solution interfaces," Journal of Applied Electrochemistry, vol. 37, no. 7, pp. 765-787, 2007.

[4] T. Yoko, A. Yuasa, K. Kamiya, and S. Sakka, "Sol-gel-derived $\mathrm{TiO}_{2}$ film semiconductor electrode for photocleavage of water. Preparation and effects of postheating treatment on the photoelectrochemical behavior," Journal of the Electrochemical Society, vol. 138, no. 8, pp. 2279-2285, 1991.

[5] N. R. de Tacconi, C. R. Chenthamarakshan, G. Yogeeswaran et al., "Nanoporous $\mathrm{TiO}_{2}$ and $\mathrm{WO}_{3}$ films by anodization of titanium and tungsten substrates: influence of process variables on morphology and photoelectrochemical response," The Journal of Physical Chemistry B, vol. 110, no. 50, pp. 25347-25355, 2006.

[6] M. Guo, P. Diao, and S. Cai, "Hydrothermal growth of perpendicularly oriented $\mathrm{ZnO}$ nanorod array film and its photoelectrochemical properties," Applied Surface Science, vol. 249, no. 1-4, pp. 71-75, 2005.

[7] S. Shen, J. Shi, P. Guo, and L. Guo, "Visible-light-driven photocatalytic water splitting on nanostructured semiconducting materials," International Journal of Nanotechnology, vol. 8, no. 6-7, pp. 523-591, 2011.

[8] R. Asahi, T. Morikawa, T. Ohwaki, K. Aoki, and Y. Taga, "Visible-light photocatalysis in nitrogen-doped titanium oxides," Science, vol. 293, no. 5528, pp. 269-271, 2001.

[9] T. Lindgren, J. M. Mwabora, E. Avandaño et al., "Photoelectrochemical and optical properties of nitrogen doped titanium dioxide films prepared by reactive DC magnetron sputtering," The Journal of Physical Chemistry B, vol. 107, no. 24, pp. 57095716, 2003.

[10] A. Hameed, M. A. Gondal, and Z. H. Yamani, "Effect of transition metal doping on photocatalytic activity of $\mathrm{WO}_{3}$ for 
water splitting under laser illumination: role of 3d-orbitals," Catalysis Communications, vol. 5, no. 11, pp. 715-719, 2004.

[11] G. Mandel, "Self-compensation limited conductivity in binary semiconductors. I. Theory," Physical Review, vol. 13, no. 4, pp. A1073-A1079, 1964.

[12] D. A. Cusano, "CdTe solar cells and photovoltaic heterojunctions in II-VI compounds," Solid State Electronics, vol. 6, no. 3, pp. 217-218, 1963.

[13] K. P. Varkey, K. P. Vijayakumar, T. Yoshida, and Y. Kashiwaba, "Spray pyrolised thin film CdS homojunction solar cell with improved performance," Renewable Energy, vol. 18, no. 4, pp. 465-472, 1999.

[14] S. Mathew, P. S. Mukerjee, and K. P. Vijayakumar, "Characterization of spray pyrolysed CdS thin film doped with $\mathrm{Cu}$," Japanese Journal of Applied Physics, vol. 34, no. 9A, pp. 49404944, 1995.

[15] H. Minoura, T. Sugiura, E. Suzuki, Y. Mizuno, Y. Ueno, and D. P. Amalnerkar, "Photoelectrochemical properties of polycrystalline films of CdS doped with Cu," Journal of the Electrochemical Society, vol. 136, no. 5, pp. 1346-1350, 1989.

[16] P. J. Sebastian, "P-type CdS thin films formed by in situ $\mathrm{Cu}$ doping in the chemical bath," Applied Physics Letters, vol. 62, no. 23, pp. 2956-2958, 1993.

[17] H. Xie, C. Tian, W. Li et al., "Preparation of p-type CdS thin films and in situ dark conductivity in vacuum deposited CdS : Cu films," Applied Surface Science, vol. 257, no. 5, pp. 16231627, 2010.

[18] S. M. Mahdavi, A. Irajizad, A. Azarian, and R. M. Tilaki, "Optical and structural properties of copper doped CdS thin films prepared by pulsed laser deposition," Scientia Iranica, vol. 15, no. 3, pp. 360-365, 2008.

[19] P. S. Patil, "Versatility of chemical spray pyrolysis technique," Materials Chemistry and Physics, vol. 59, no. 3, pp. 185-198, 1999.

[20] M. T. Li, J. Z. Su, and L. J. Guo, "Preparation and characterization of $\mathrm{ZnIn}_{2} \mathrm{~S}_{4}$ thin films deposited by spray pyrolysis for hydrogen production," International Journal of Hydrogen Energy, vol. 33, no. 12, pp. 2891-2896, 2008.

[21] K. Nishidate, T. Sato, Y. Matsukura, M. Baba, M. Hasegawa, and T. Sasaki, "Density-functional electronic structure calculations for native defects and Cu impurities in CdS," Physical Review B, vol. 74, no. 3, Article ID 035210, 8 pages, 2006.

[22] M. F. Montemor, M. G. S. Ferreira, N. E. Hakiki, and M. da Cunha Belo, "Chemical composition and electronic structure of the oxide films formed on $316 \mathrm{~L}$ stainless steel and nickel based alloys in high temperature aqueous environments," Corrosion Science, vol. 42, no. 9, pp. 1635-1650, 2000.

[23] L. M. Peter and K. G. U. Wijayantha, "Electron transport and back reaction in dye sensitized nanocrystalline photovoltaic cells," Electrochimica Acta, vol. 45, no. 28, pp. 4543-4551, 2000. 

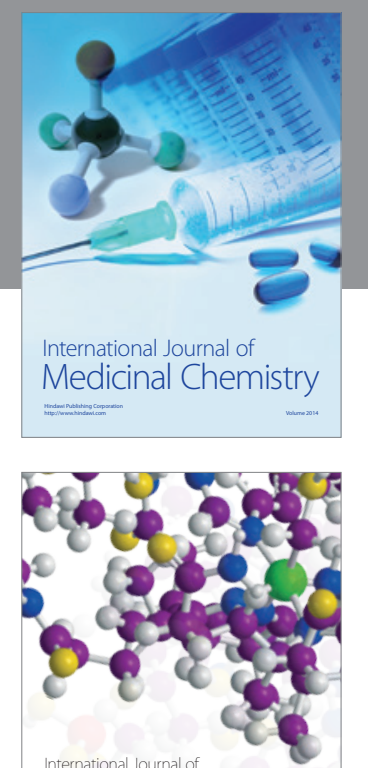

\section{Carbohydrate} Chemistry

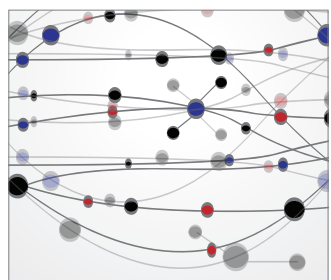

The Scientific World Journal
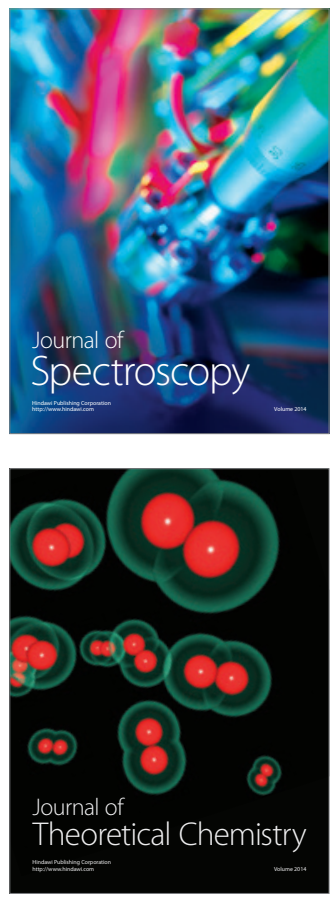
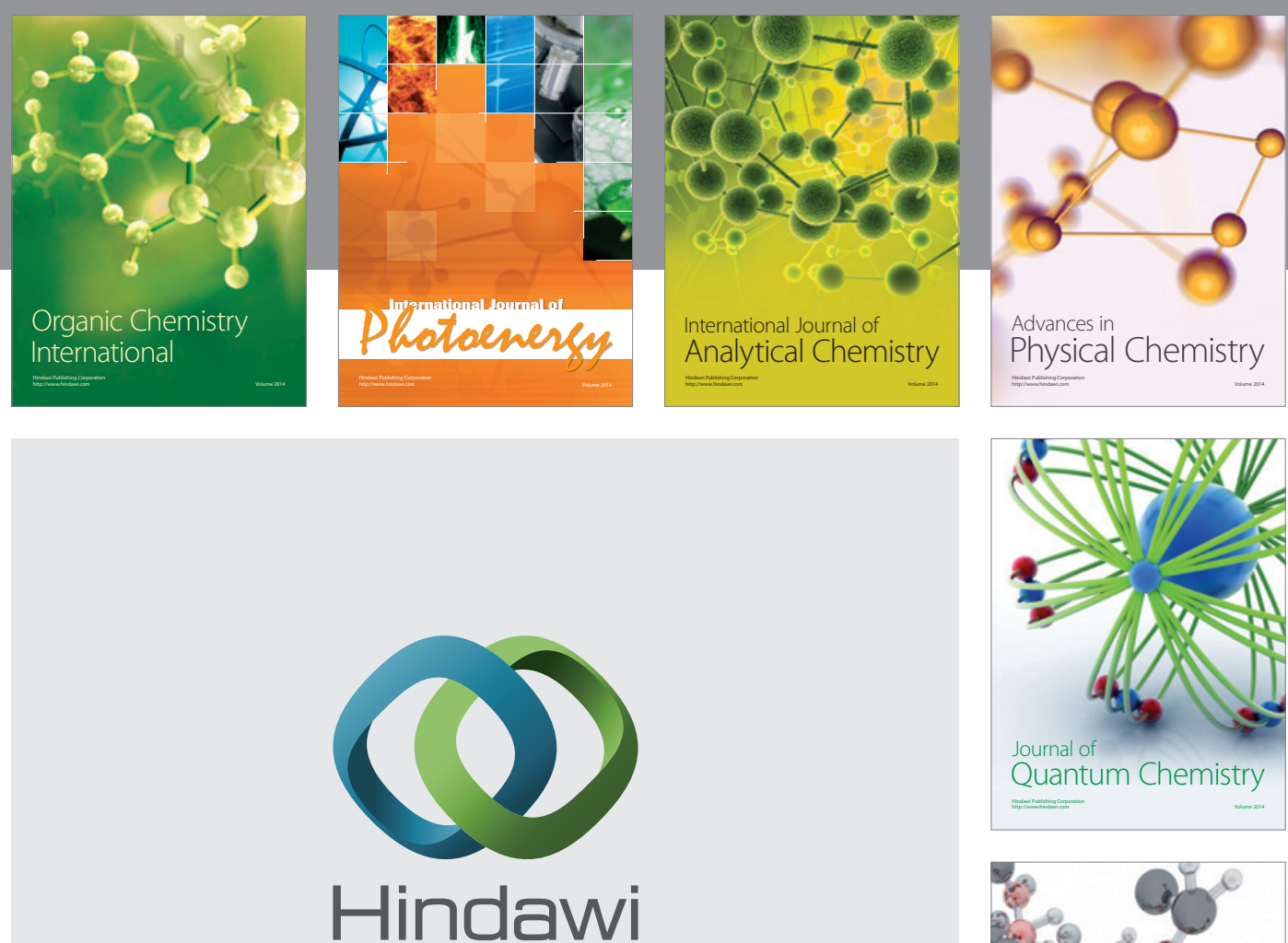

Submit your manuscripts at

http://www.hindawi.com

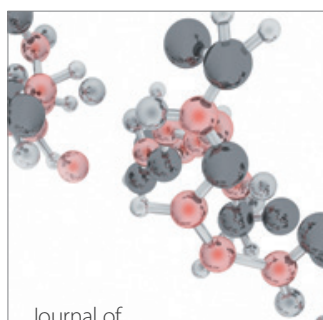

Analytical Methods

in Chemistry

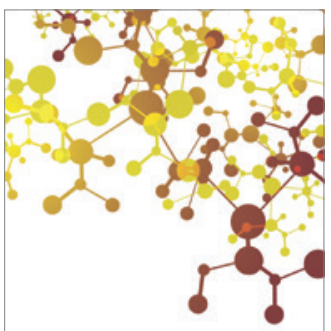

Journal of

Applied Chemistry

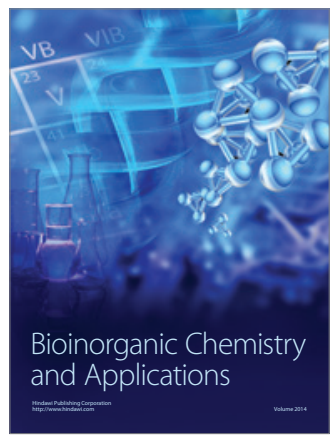

Inorganic Chemistry
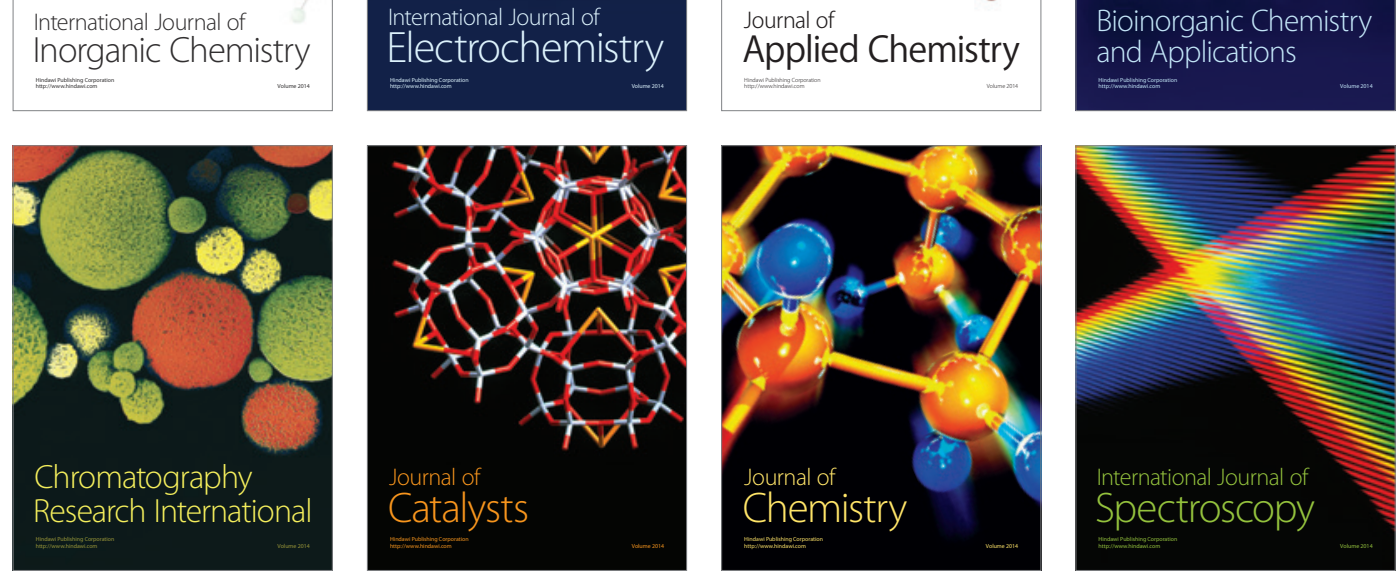